\title{
O processo judicial eletrônico, o direito ao desenvolvimento e a boa governança: o caminho para a sustentabilidade ${ }^{1}$
}

\author{
Fernanda Netto Estanislau ${ }^{2}$ \\ Magno Frederici Gomes ${ }^{3}$
}

\begin{abstract}
Resumo: O presente artigo estuda o Processo Judicial eletrônico, o direito ao desenvolvimento e a boa governança como um possível caminho para a sustentabilidade. O texto procura abordar a preocupação da diminuição de gastos e da busca pela transparência e a distância entre a sustentabilidade e o acesso ao Poder Judiciário. Trata-se de um artigo teórico-documental, com técnica dedutiva, com cotejamento das leis existentes e doutrina sobre a boa governança. $\mathrm{O}$ estudo propõe uma reflexão sobre a implantação do Processo Judicial eletrônico e a responsabilidade da sociedade frente ao desafio da sustentabilidade e da manutenção de garantias constitucionais, busca-se entender o que é preciso para se efetivar a governança no Processo Judicial eletrônico e se apenas as resoluções do Conselho Nacional de Justiça serão capazes de implementar a boa governança. Conclui-se que tanto o direito ao desenvolvimento quanto a existência de uma boa governança só se fazem possível diante do respeito dos direitos fundamentais, da garantia de participação de todos, da transparência em todos os atos e na justiça social.
\end{abstract}

Palavras-chave: Direito ao desenvolvimento; Boa governança; Sustentabilidade; Processo Judicial eletrônico.

\section{El proceso judicial, electrónicos, el derecho al desarrollo y la buena gobernanza: el camino hacia la sostenibilidad}

Resumen: Este artículo examina el proceso judicial, el derecho al desarrollo y el buen gobierno como un posible camino para la sostenibilidad. El texto trata de abordar el problema de la disminución de los gastos y la búsqueda de la transparencia y de la distancia entre la sostenibilidad y el acceso a la judicatura. Es un artículo teórico-documental, con técnica deductiva, con la comparación de las leyes existentes y la doctrina sobre el buen gobierno. El estudio propone una reflexión sobre la aplicación del proceso judicial y la responsabilidad de la sociedad para hacer frente a los retos de la sostenibilidad y el mantenimiento de las garantías constitucionales, se trata de comprender lo que se necesita para hacer el gobierno en el proceso judicial y si sólo las resoluciones del Consejo Nacional de Justicia será capaz de aplicar una buena gestión. Se concluye que tanto el derecho al desarrollo acerca de la existencia de una buena gobernanza sólo se hacen posible antes de que el respeto de los derechos fundamentales, asegurando la participación de todos, la transparencia en todas las acciones y la justicia social.

Palabras clave: Derecho al Desarrollo; Gobernabilidad; Sostenibilidad.

SUMÁRIO: Considerações iniciais. $1 \mathrm{O}$ acesso à justiça após a implantação do Processo Judicial eletrônico. $2 \mathrm{O}$ princípio da informação frente ao Processo Judicial eletrônico. $3 \mathrm{O}$ desenvolvimento como direito. 4 A boa governança. Considerações finais. Referências.

\section{Considerações iniciais}

A todo momento se observa a preocupação com a sustentabilidade, com os direitos humanos e com uma política que seja possível se atingir os objetivos sociais e manter o mercado econômico ao mesmo tempo.

Ao se deparar com a Encíclica Laudato Si (Louvado sejas) do Santo Padre Francisco sobre o cuidado da casa comum, e as declarações internacionais existentes, pode-se perceber que o mundo clama por uma solução que concilie economia, desenvolvimento, crescimento e sustentabilidade. 
É indiscutível que a inobservância do resultado das ações perante ao meio ambiente acabam por se tornar catastróficas a medida que se entende que todos, uma hora ou outra, passarão a sofrer as consequências das atitudes dos demais.

Objetiva-se, com o presente texto, o estudo do Processo Judicial eletrônico (PJe) frente o direito ao desenvolvimento e a boa governança como um possível caminho para a sustentabilidade. Busca-se entender o que é preciso para se efetivar a governança no Processo Judicial eletrônico e se apenas as resoluções do Conselho Nacional de Justiça serão capazes de implementar a boa governança.

A delimitação do tema se justifica no fato dos inúmeros questionamentos que se tem feito sobre a possibilidade ou não de se possuir um processo judicial totalmente eletrônico, garantindo o acesso as informações, ao Poder Judiciário, se ter o direito ao desenvolvimento como direito fundamental. Ademais, planteia-se que a boa governança pode e deve ser uma parceira para a sustentabilidade perante a realidade social.

A metodologia empregada é a teórico documental em uma pesquisa qualitativa, com técnica dedutiva, em que são analisados a legislação pertinente e a doutrina, cujo marco teórico é a obra coordenada por Piovesan e Soares (2010) e o livro de Sampaio (2007).

Assim, a proposta do texto é fazer um estudo específico sobre o PJe e o direito ao desenvolvimento como direito fundamental e a boa governança como um possível caminho para a sustentabilidade

\section{O acesso à justiça após a implantação do processo judicial eletrônico}

Ao seguir os preceitos constitucionais de que todos deverão ser tratados sem discriminação $\mathrm{e}^{4}$ os direitos humanos existentes hoje, o acesso à jurisdição após a implantação do processo eletrônico necessita ser estudado de forma mais minuciosa.

Respeitado o fato de que o acesso à jurisdição não é apenas a possibilidade do cidadão de ingressar em Juízo mas, também, a garantia do seguimento do devido processo legal garantindo à todos o direito de defesa e ampla atuação ao longo de todo o processo, com a devida apresentação das provas, fatos e testemunhas, o PJe deve garantir ao menos a verificação dos autos por qualquer interessado que se apresente.

De acordo com Bobbio (1992, p. 28) "a ideia de que o homem enquanto tal tem direitos, por natureza, que ninguém (nem mesmo o Estado) lhe pode subtrair, e que ele mesmo não pode alienar [...] foi elaborada pelo jus naturalismo moderno. Seu pai é John Locke" (BOBBIO, 1992, p. 28).

Pode-se perceber que, com a implantação da necessidade da assinatura digital, imposta pela ICP-Brasil, bem como todos os demais programas e dispositivos necessário para acessar o PJe, a implantação da tecnologia não garante o acesso à jurisdição, mas acaba por causar em alguns momentos um verdadeiro obstáculo.

Segundo Sachs (2002, p. 85-86) "a sustentabilidade social acontece através do alcance de um patamar razoável de homogeneidade social, distribuição de renda justa, qualidade de vida e igualdade no acesso aos recursos e serviços sociais; já a sustentabilidade econômica envolve dentre outras coisas o acesso à ciência e a tecnologia." 
Assim, averígua-se que o PJe vai contra o que se entende por sustentabilidade social e econômica, já que não leva em consideração que a realidade brasileira está bem longe de garantir acesso a tecnologia à todos, contando ainda com inúmeras pessoas que não possuem condições financeiras, conhecimento em informática nem mesmo acesso à internet.

Ao informatizar o processo, buscando o mínimo de contato humano entre o Poder Judiciário e as partes, o PJe acabou por excluir todo aquele cidadão que não foi alfabetizado, dificultando ainda para as demais informações básicas do processo, como andamento e cópias dos mesmos. Gauchet (2002), sustentou que: "os direitos humanos se tornaram efetivamente, por uma imprevisível evolução de nossas sociedades, a norma organizadora da consciência coletiva e o padrão da ação pública" (GAUCHET, 2002, p. 330).

Desta forma, o acesso à jurisdição se vê limitado aos profissionais da área do direito que possuem certificação digital, internet, programas de última geração, leitora de certificação digital dentre outros requisitos que hoje se fazem necessários.

Como um direito humano a ser respeitado, de forma a garantir o completo exercício da cidadania, o acesso à jurisdição se mostra consagrado na $\mathrm{CR} / 1988$, que traz em seu art. 5º inciso XXXV, o preceito que "a lei não excluirá da apreciação do Poder Judiciário lesão ou ameaça a direito" (BRASIL, 1988). Assim, fica assegurado a todo cidadão o direito de utilizar-se do Poder Judiciário todas as vezes que se sentir lesado, constrangido ou privado de seus direitos. Entende-se o acesso à jurisdição como uma das formas diretas de se alcançar uma possível justiça social.

Como um retrocesso histórico o PJe corre o risco de excluir do acesso ao Poder Judiciário as pessoas menos favorecidas, limitando até mesmo seu acesso e utilização a elite possuidora de conhecimentos técnicos em informática e detentora de um privilégio econômico.

\section{O princípio da informação frente ao processo judicial eletrônico}

Dizer que o processo pode ser acessado via internet, está longe de ser uma forma de garantir o acesso de todos a informação contida nos processos judiciais eletrônicos.

Verdadeiramente precisa-se entender que o princípio da informação no processo judicial, seja ele eletrônico ou não, é essencial para que a justiça aconteça, vez que apenas através da informação é que se pode garantir que todas as partes do processo estiveram em pé de igualdade no desenrolar de todos os atos e procedimentos do processo.

Deve o direito de se informar ser respeitado de forma a garantir a publicidade dos processos e o direito de todos de ter acesso aos mesmos, salvo os casos justificados de segredo de justiça. Esse princípio ainda deve ser analisado de duas formas, como garantia de informar e de se informar do cidadão.

Assim o direito de todos terem acesso às informações esta previsto na CR/1988 em seu art. $5^{\circ}$, incisos XIV ${ }^{5}, \mathrm{XXXIII}^{6}$ e XXXIV ${ }^{7}$, bem como, o dever do Poder Público de informar todos os seus atos, justificando-os e os tornando público.

O PJe ao minimizar todo o contato humano, limitando o acesso aos processos aos operadores de direito que possuem cadastro e assinatura digital acaba obviamente por limitar o acesso ao Poder Judiciário, dificultando inclusive que os terceiros interessados possam se manifestar e ter acesso aos processos de forma livre. 
Outra consequência, além da falta de publicidade, é o fato que desta forma fica também restringido o poder de fiscalização dos cidadãos interessados, que não mais conseguem acompanhar as decisões judiciais e as motivações existentes nas mesmas.

Pode-se dizer que a transparência dos atos processuais existentes no PJe, de forma geral, se encontra comprometida. De acordo com Wambier: "existe para vedar o obstáculo ao conhecimento. Todos têm o direito de acesso aos atos do processo, exatamente como meio de se dar transparência à atividade jurisdicional" (WAMBIER, 2000, p. 80).

Por óbvio que o princípio da informação não pode ser encarado de forma a ignorar o princípio da intimidade. Está-se aqui defendendo a informação daquilo que deve ser público e não o escancaramento indiscriminado de qualquer informação. Essa é a orientação do Supremo Tribunal Federal - STF (2000, s.p.):

\footnotetext{
Os direitos e garantias individuais não têm caráter absoluto. Não há, no sistema constitucional brasileiro, direitos ou garantias que se revistam de caráter absoluto, mesmo porque razões de relevante interesse público ou exigências derivadas do princípio de convivência das liberdades legitimam, ainda que excepcionalmente, a adoção, por parte dos órgãos estatais, de medidas restritivas das prerrogativas individuais ou coletivas, desde que respeitados os termos estabelecidos pela própria Constituição. O estatuto constitucional das liberdades públicas, ao delinear o regime jurídico a que estas estão sujeitas - e considerado o substrato ético que as informa - permite que sobre elas incidam limitações de ordem jurídica, destinadas, de um lado, a proteger a integridade do interesse social e, de outro, a assegurar a coexistência harmoniosa das liberdades, pois nenhum direito ou garantia pode ser exercido em detrimento da ordem pública ou com desrespeito aos direitos e garantias de terceiros.
}

Assim sendo, o que se expõe aqui é a necessidade da publicidade e acesso à informação que pertence a todos e não aquela que de alguma forma possa ferir o direito de alguém. Com a devida observação ao art. $5^{\circ}$, inciso X, da CR/1988 ${ }^{8}$, que protege e garante a inviolabilidade da intimidade, da vida privada, da honra e da imagem das pessoas, salvaguardando "o direito a indenização pelo dano material ou moral decorrente de sua violação" (BRASIL, 1988).

De certo que toda informação que for restringida deve ser feita de forma justificada e com base na Lei. Veja que a CR/1988 não se esquivou do assunto ao estabelecer que "a lei só poderá restringir a publicidade dos atos processuais quando a defesa da intimidade ou o interesse social o exigirem" (BRASIL, 1988, art. 5º, inciso LX).

\section{O desenvolvimento como direito}

A palavra desenvolvimento está diretamente relacionada à ideia de crescimento e progresso. O desenvolvimento sustentável foi definido de forma mais aceitável pela Comissão Mundial sobre Meio Ambiente e Desenvolvimento, criada pelas Nações Unidas com o objetivo de discutir e estabelecer meios de harmonizar o desenvolvimento econômico e a conservação ambiental, in verbis: "o desenvolvimento capaz de suprir as necessidades da geração atual, sem comprometer a capacidade de atender as necessidades das futuras gerações. É o desenvolvimento que não esgota os recursos para o futuro" (COMISSÃO MUNDIAL PARA O MEIO AMBIENTE E O DESENVOLVIMENTO - CMMAD, s.p., 1988). 
Segundo Veiga (2009, p. 157) existe uma diferença entre crescimento nos dias de hoje e antigamente:

crescimento antigamente significava a devora dos recursos naturais pela força física do trabalho humano. O crescimento moderno passou cada vez a depender do uso inteligente das inovações que tornam o trabalho mais decentes e qualificados, além de conservar os ecossistemas (VEIGA, 2009, p. 157).

Hoje todos sabem que as atitudes adotadas resultam em consequências no meio ambiente. Mas não se sabe o que se deve parar de fazer ou o que fazer. Lovelock (2006, p. 22), nesse sentido mostra que mais do que dizer que defende, é necessário a atitude de defender a Terra:

A maioria acredita que algo desagradável poderá ocorrer em breve mas estamos tão confusos como em 1938 quanto a forma que assumirá é o que fazer a respeito. Nossa reação até agora tem sido como antes da segunda guerra mundial, uma tentativa de apaziguamento. O protocolo de Kyoto foi assustadoramente parecido com o acordo de Munique, os políticos procurando mostrar que reagem, mas na verdade tentando ganhar tempo. Por sermos animais tribais, a tribo não age unida enquanto não percebe um perigo real e presente. Essa percepção ainda não ocorreu (LOVELOCK, 2006, p. 22).

Para Piovesan (2000, p. 35):

a Declaração de 1948 introduziu a concepção contemporânea de direitos humanos, marcada pela universalidade e indivisibilidade desses direitos, pois ao consagrar direitos civis e políticos e direitos econômicos sociais e culturais, a Declaração combina o discurso liberal e o discurso social da cidadania ao conjugar o valor da liberdade ao valor da igualdade (PIOVESAN, 2000, p. 35).

Para Lovelock (2006, p. 36):

A declaração de Amsterdã representou um passo importante como a adoção da teoria Gaia como modelo de trabalho para Terra. Com tudo, divisões territoriais e dúvidas persistentes impediram que os cientistas que assinaram a declaração enunciassem a meta da Terra autoreguladora, que é, de acordo com a minha teoria, sustentar a habitabilidade (LOVELOCK, 2006, p. 36).

Para Leff (2006), as questões relacionadas ao meio ambiente devem ser tratadas como um problema social:

\begin{abstract}
A questão ambiental aparece como uma problemática social e ecológica generalizada de alcance planetário, que mexe com todos os âmbitos da organização social, do aparato do Estado e todos os grupos e classes sociais. Isso induz um amplo e complexo processo de transformações epistêmicas no campo do conhecimento e do saber, das ideologias teóricas e práticas, dos paradigmas científicos e os programas de pesquisa (LEFF, 2006, p. 282).
\end{abstract}

Guerra (2006, p. 80) sobre o Relatório de Brundtland, traz a tese a respeito do desenvolvimento sustentável: "O Desenvolvimento capaz de manter o progresso humano não apenas em alguns lugares por alguns anos, mas em todo o planeta até um futuro longínquo" (GUERRA, 2006, p. 80).

A Declaração sobre o Direito ao Desenvolvimento de 1986 pode ser considerada como o principal documento acerca do direito ao desenvolvimento, sendo vista por muitos como um gran- 
de avanço no tocante aos direitos humanos. Uma vez que, "sob a ótica normativa internacional, está definitivamente superada a concepção de que os direitos sociais, econômicos e culturais não são direitos legais" (PIOVESAN, 2010, p. 101).

Piovesan (2010) identifica ainda que:

para a Declaração de 1986 o desenvolvimento compreende um processo econômico, social, cultural e político, - com o objetivo de assegurar a constante melhoria do bem-estar da população e dos indivíduos, com base em sua ativa, livre e significativa participação neste processo, orientado pela justa distribuição dos benefícios dele resultantes (PIOVESAN, 2010, p. 102).

A Encíclica do Papa Francisco, Laudato Si, publicada em junho de 2015, alerta para a necessidade de direcionar as mudanças do mundo para um desenvolvimento humano:

\begin{abstract}
A contínua aceleração das mudanças na humanidade e no planeta junta-se, hoje, à intensificação dos ritmos de vida e trabalho, que alguns, em espanhol, designam por«rapidación». Embora a mudança faça parte da dinâmica dos sistemas complexos, a velocidade que hoje lhe impõem as ações humanas contrasta com a lentidão natural da evolução biológica. A isto vem juntar-se o problema de que os objetivos desta mudança rápida e constante não estão necessariamente orientados para o bem comum e para um desenvolvimento humano sustentável e integral. A mudança é algo desejável [...] (PAPA FRANCISCO, 2015, p. 4).
\end{abstract}

Leff (2002) aduz que a sustentabilidade não pode ser alcançada apenas com relação ao meio ambiente, na natureza: "o ambiente não é a ecologia, mas a complexidade do mundo; é um saber sobre as formas de apropriação do mundo e da natureza através das relações de poder que se inscreveram nas formas dominantes de conhecimento" (LEFF, 2002, p. 17).

Assim Leff (2002) acredita que o ambiente "é o Outro do pensamento metafísico, do lógos científico e da racionalidade econômica" (LEFF, 2002, p. 161). E o saber ambiental, proposto pelo autor (2002), é um "saber sobre esse campo externalizado pela racionalidade econômica, científica e tecnológica da modernidade; mas, por sua vez, conota os saberes marginalizados e subjugados pela centralidade do lógos científico" (LEFF, 2002, p. 160). Deve-se ter em mente que o desenvolvimento deve direcionar para o uso inteligente do que se possui, com o intuito de alcançar os objetivos sem esgotar ou destruir aquilo que se usa ou utiliza. Lovelock (2006, p. 20) revela o bem e o mal de cada um na utilização da Terra:

Somos uma espécie equivalente aquela dupla esquizoide do romance de Stevenson i o médico e o monstro. Temos a capacidade de destruição desastrosa, mas também o potencial de edificar uma civilização magnífica. O monstro nos levou a usar mal a tecnologia abusamos da energia e superpovoado a terra, mas não é abandonando a tecnologia que sustentaremos a civilização. Pelo contrário, temos de usa-la sabiamente, como faria o médico, tendo em mira a saúde da terra, não a de pessoas. Vai ser tarde demais para desenvolvimento sustentável, precisamos é de uma retirada sustentável (LOVELOCK, 2006, p. 20).

Mesmo com a existência da Declaração de 1986, ainda existem inúmeros desafios para o reconhecimento e efetivação ao direito do desenvolvimento. Pode-se citar, por exemplo, a noção de caridade que se tem quando se propõe o direito ao desenvolvimento, "a caridade está presente, isto sim, na religião, aqui, no âmbito social, seja na perspectiva nacional ou mesmo internacional, se trata de um dever, pois o direito ao desenvolvimento, segundo a declaração, está submetida à lógica dos direitos humanos" (MARKS, 2010, p. 24). 
Neste sentido Marks (2010) ainda afirma: "E não há como negar que a lógica que influenciou a declaração foi sem dúvida aquela presente nas teorias dos direitos naturais. Dentro desta perspectiva a pessoa é o centro do direito ao desenvolvimento" (MARKS, 2010, p. 25).

Assim, percebe-se que não se trata apenas de escrever uma lei, mas sim de transformar o entendimento no sentindo de reconhecer que todos possuem de fato o direito ao desenvolvimento. Sempre atentos ao fato que o conceito de legitimidade é enfrentado de forma subjetiva na teoria weberiana: "parte da atitude do sujeito que legitima com respeito ao poder de legitimar, isto é, de uma 'crença', seja na validade do que é racional (segundo um valor ou propósito), na força da tradição ou na virtude do carisma" (BOBBIO, 1988, p. 172).

Desta forma, o direito ao desenvolvimento desperta no sentido de entender que todos devem assumir suas ações, compreendendo a responsabilidade individual e coletiva pelos fatos que afetam o indivíduo. Dessa forma, é possível enunciar que: “[...] é dever dos Estados encorajar a participação popular em todas as esferas como um importante fator ao direito ao desenvolvimento" (PIOVESAN, 2010, p. 103).

Essa participação deve se efetivar no sentindo de garantir a todos, a plenitude dos direitos e assim não repetir os erros históricos do passado. Mais uma vez ao observar as palavras do Papa Francisco percebe-se o motivo que leva a tais preocupações:

[...] contemplando o mundo, damo-nos conta de que este nível de intervenção humana, muitas vezes ao serviço da finança e do consumismo, faz com que esta terra onde vivemos se torne realmente menos rica e bela, cada vez mais limitada e cinzenta, enquanto ao mesmo tempo o desenvolvimento da tecnologia e das ofertas de consumo continua a avançar sem limites. Assim, parece que nos iludimos de poder substituir uma beleza insuprível e irrecuperável por outra criada por nós [...] (PAPA FRANCISCO, 2015, p. 5).

Para evitar uma catástrofe ainda maior é necessário aceitar que não é possível prever o futuro, e que as conjecturas acabam por resultar em uma verdadeira perda para todos, Lovelock (2006) afirma a necessidade de evoluir com relação ao sistema da Terra:

A ciência busca ser global e mais do que uma coleção dispersa de disciplinas separadas, mas mesmo os que adotam uma abordagem sistêmica da ciência seriam os primeiros a admitir que nossa compreensão do sistema da Terra não é muito superior a de um médico do século XIX em relação ao seu paciente (LOVELOCK, 2006, p .19).

Para que o conhecimento possa de fato resultar em proteção ambiental é importante "a busca de um paradigma globalizante do conhecimento, a organização sistêmica do saber e a uniformização conceitual por meio de uma metalinguagem interdisciplinar” (LEFF, 2002, p. 163).

Pois todo conhecimento passa por um processo de construção que quanto mais interdisciplinar mais complexo e completo pode-se apresentar, “internalização de uma 'dimensão' ambiental generalizável aos diferentes paradigmas do conhecimento" (LEFF, 2002, p. 163).

O texto de Leff (2002) que melhor apresenta essa questão do saber ambiental é:

o saber ambiental a ser constituído em relação com seus impensáveis, na reflexão do pensamento sobre o já pensado, na abertura do ser em seu porvir, em sua relação com o infinito, no horizonte do possível e o que ainda não é. Nesse sentido, constrói-se um novo saber, uma nova racionalidade e um futuro sustentável (LEFF, 2002, p. 19). 
Assim, segundo Leff (2006):

o saber ambiental não se conforma uma doutrina homogênea, fechada e acabada; emerge e se desdobra em um campo de formações ideológicas heterogêneas e dispersas, constituídas por uma multiplicidade de interesses e práticas sociais; nas estratégias de poder inscritas no discurso teórico das ciências (economia, ecologia, antropologia, direito); no saber camponês e das comunidades indígenas integrado a seus sistemas gnosiológicos, seus valores culturais e suas práticas tradicionais de uso da natureza; no saber ambiental inscrito nas políticas de desenvolvimento sustentável, em suas estratégias e em suas práticas discursivas, e em seus instrumentos normativos e jurídicos (LEFF, 2006, p. 280281).

Em outras palavras:

o diálogo de saberes é formulado a partir do reconhecimento dos saberes - autóctones, tradicionais, locais - que aportam suas experiências e se somam ao conhecimento científico e especializado; mas implica, por sua vez, o dissenso e a ruptura com uma via homogênea para a sustentabilidade (LEFF, 2006, p. 376-377).

De forma resumida para Leff (2004), “o saber ambiental vai além da ambientalização do conhecimento existente [...] transforma o conhecimento para construir uma nova ordem social [...] está comprometido com a utopia, através de novas formas de posicionamento dos sujeitos da história face ao conhecimento" (LEFF, 2004, p. 235).

Segundo Bobbio (1992) "a ideia de que o homem enquanto tal tem direitos, por natureza, que ninguém (nem mesmo o Estado) lhe pode subtrair, e que ele mesmo não pode alienar [...] foi elaborada pelo jus naturalismo moderno. Seu pai é John Locke” (BOBBIO, 1992, p. 28).

Essa intervenção se faz oportuna no sentido de que a sociedade possui uma verdadeira preocupação de manter os bens sem observar os prejuízos causados à outrem. Como exemplo, destaca-se aqueles que acreditam que a existência da sociedade civil se dá em razão da imprescindibilidade de proteção da propriedade:

A única maneira pela qual alguém se despoja de sua liberdade natural e se coloca dentro das limitações da sociedade civil através de acordo com outros homens para se associarem e se unirem em uma comunidade para uma vida confortável, segura e pacífica uns com os outros, desfrutando com segurança de suas propriedades e melhor protegidos contra aqueles que não são daquela comunidade.

(LOCKE, 1994, p. 61).

Tudo isso leva a perceber que de fato é necessária uma conscientização global acerca do direito ao desenvolvimento. Piovesan (2010, p. 108) ainda destaca que são necessárias ações em conjunto para que se alcance o fim desejado:

Assim, as dimensões centrais do direito humano ao desenvolvimento, englobam uma ampla dimensão de facetas, pois contempla a justiça social, a participação e accountability, programas e políticas nacionais, e a cooperação internacional, em resposta ao contexto mundial que o confronta (PIOVESAN, 2010, p. 108).

Desta forma Fachin (2010) ressalta:

Estado brasileiro seja signatário da referida declaração de 1986, que sistematiza o direito ao desenvolvimento, não há no direito (constitucional) pátrio qualquer menção ao direito ao desenvolvimento como um direito fundamental neste sentido abrangente e inclusivo que trata o documento internacional (FACHIN, 2010, p. 179). 
Por óbvio que frente a esta ausência o Poder Judiciário acaba por exercer um significativo papel para garantir o direito ao desenvolvimento de todos.

Assim destaca-se a necessidade da independência do Poder Judiciário e paralelamente a necessidade de controle do mesmo, o que ensejou a criação do Conselho Nacional de Justiça (CNJ).

Fica a cargo do CNJ o controle interno do Poder Judiciário, podendo apreciar a legalidade dos atos administrativos praticados por membros ou órgãos do Poder Judiciário, desconstituí-los, revê-los ou fixar prazo para que se adotem as providências necessárias ao exato cumprimento da Lei (art. 103-B, $\S 4^{\circ}$, II) (SAMPAIO, 2007, p. 139).

Mesmo não pertencendo ao cerne de tema, é possível destacar aqui a legitimidade do CNJ, matéria discutida e julgada pelo STF, através da Ação Direta de Inconstitucionalidade (ADI) $\mathrm{n}^{\circ}$ 3.367-DF. Segue ementa:

\begin{abstract}
ADI3367/DF-DISTRITOFEDERAL-AÇÃODIRETADEINCONSTITUCIONALIDADE Relator(a): Min. CEZAR PELUSO - Julgamento: 13/04/2005 - Órgão Julgador: Tribunal Pleno REQTE.(S): ASSOCIAÇÃO DOS MAGISTRADOS BRASILEIROS - AMB REQDO.(A/S): CONGRESSO NACIONAL EMENTAS: 1. AÇÃO. Condição. Interesse processual, ou de agir. Caracterização. Ação direta de inconstitucionalidade. Propositura antes da publicação oficialdaEmenda Constitucional ${ }^{\circ} . .45 / 2004$.Publicaçãosuperveniente, antes do julgamento da causa. Suficiência. Carência da ação não configurada. Preliminar repelida. Inteligência do art. 267, VI, do CPC. Devendo as condições da ação coexistir à data da sentença, considera-se presente o interesse processual, ou de agir, em ação direta de inconstitucionalidade de Emenda Constitucional que só foi publicada, oficialmente, no curso do processo, mas antes da sentença. 2. INCONSTITUCIONALIDADE. Ação direta. Emenda Constitucional no. 45/2004. Poder Judiciário. Conselho Nacional de Justiça. Instituição e disciplina. Natureza meramente administrativa. Órgão interno de controle administrativo, financeiro e disciplinar da magistratura. Constitucionalidade reconhecida. Separação e independência dos Poderes. História, significado e alcance concreto do princípio. Ofensa a cláusula constitucional imutável (cláusula pétrea). Inexistência. Subsistência do núcleo político do princípio, mediante preservação da função jurisdicional, típica do Judiciário, e das condições materiais do seu exercício imparcial e independente. Precedentes e súmula 649. Inaplicabilidade ao caso. Interpretação dos arts. $2^{\circ}$. e $60, \S 4^{\circ}$., III, da CF.
\end{abstract}

Prossegue Sampaio (2007, p. 252) quanto a eventual desequilíbrio entre os poderes ou restrição à autonomia dos tribunais que, com acerto, o CNJ: “é um órgão da estrutura do Judiciário sem função jurisdicional, especialmente formado por maioria de magistrados, com a tarefa exata de zelar pela autonomia do Poder, não atentar contra ela, sobretudo porque a autonomia é conferida ao Poder e não aos órgãos isoladamente" (SAMPAIO, 2007, p. 252).

Termina asseverando que:

[...] não houve atentado às competências privativas dos tribunais, enumeradas no artigo constitucional 96, podendo ainda agora plenamente elaborar e aprovar seus regimentos internos, eleger os corpos diretivos, organizar secretarias e serviços auxiliares, prover cargos de juiz e serventuários, bem como os demais atos de gestão administrativa (SAMPAIO, 2007, p. 252).

O poder disciplinar do CNJ deve ter sua atuação completamente baseada na CR/1988 e na Lei Orgânica da Magistratura, sendo que qualquer "desvio de finalidade" pode e será revisto pelo STF, como afirma Sampaio (2007, p. 253).

Também é nesse sentido o entendimento do CNJ: 
A teor do disposto no $\S 4^{\circ}$. do Art. 103-B da Constituição Federal de 1988, ao Conselho Nacional de Justiça compete, precipuamente, 'o controle da atuação administrativa e financeira do Poder Judiciário e do cumprimento dos deveres funcionais dos juízes’. Neste contexto, a competência fixada para o referido Conselho é restrita ao âmbito administrativo do Poder Judiciário, não podendo ocorrer intervenção em conteúdo de decisão judicial, para corrigir eventual vício de ilegalidade ou nulidade (CNJ - RD 2008100000015082 - Rel. Min. Corregedor Nacional Gilson Dipp - 70a . Sessão - j. 23.09.2008 - DJU 13.10.2008 - Ementa não oficial).

Para Sampaio (2007, p. 282), o poder de polícia exercido pelo CNJ está muito mais ligado ao exercício administrativo do Poder Judiciário:

O poder de policia, por exemplo, exige uma serie de normas que escapa da sua competência regulamentar. Se aceitássemos a automática aplicação do principio da instrumentalidade, correríamos o risco de por abaixo as estruturas do Estado de Direito. É certo que o poder de policia do Conselho se exerce sobre atividade publica e te caráter organizatório, não envolvendo, em regra, direitos fundamentais (SAMPAIO, 2007, p. 282).

Obviamente que a existência do CNJ por si só não garante a efetividade, a celeridade, a transparência nem tão pouco a eficiência do Poder Judiciário. Mas obviamente é um passo para a transparência e controle do Poder Judiciário.

Na mesma esteira, o PJe também não pode ser visto como uma solução automática para a sustentabilidade.

Pelo exposto, tem-se que a criação do $\mathrm{CNJ}$, a informatização dos processos e dos procedimentos por meio do PJe, faz parte da busca da sustentabilidade e da efetivação do direito ao desenvolvimento que é um direito exigível na órbita nacional e internacional.

Necessário se faz observar as limitações jurídicas existentes. Essa é a orientação do STF:

Os direitos e garantias individuais não têm caráter absoluto. Não há, no sistema constitucional brasileiro, direitos ou garantias que se revistam de caráter absoluto, mesmo porque razões de relevante interesse público ou exigências derivadas do princípio de convivência das liberdades legitimam, ainda que excepcionalmente, a adoção, por parte dos órgãos estatais, de medidas restritivas das prerrogativas individuais ou coletivas, desde que respeitados os termos estabelecidos pela própria Constituição. O estatuto constitucional das liberdades públicas, ao delinear o regime jurídico a que estas estão sujeitas - e considerado o substrato ético que as informa - permite que sobre elas incidam limitações de ordem jurídica, destinadas, de um lado, a proteger a integridade do interesse social e, de outro, a assegurar a coexistência harmoniosa das liberdades, pois nenhum direito ou garantia pode ser exercido em detrimento da ordem pública ou com desrespeito aos direitos e garantias de terceiros ${ }^{9}$.

Necessário o equilíbrio entre o direito individual e o direito coletivo de forma que se possa conseguir superar o desafio de proteger o que o Papa Francisco chama de "nossa casa" e ainda conseguir garantir à todos o direito ao desenvolvimento.

\section{A Boa governança}

Segundo Diniz (1995, p. 400) a expressão governança surge "tendo em vista aprofundar o conhecimento das condições que garantem um Estado eficiente". Diante da interação internacional existente surge a governança global, que tem como base gerar regras entre nações diferentes para um bom desenvolvimento mundial. 
Para Santos (1997, p.340-341): "A ideia de que uma "boa" governança é um requisito fundamental para um desenvolvimento sustentado, que incorpora ao crescimento econômico equidade social e também direitos humanos" (SANTOS, 1997, p. 340-341).

Assim, a crescente participação da sociedade em expor suas ideias e se organizar por seus ideais trás uma crescente aclamação por uma governança real aonde a transparência e a participação sejam fatores comuns e não exceções nas tomadas de decisões.

Com relação a Organização das Nações Unidas (ONU), existe a Resolução nº 31/1996 do Conselho Econômico e Social (ECOSOC), determinando as bases para as relações de consulta entre as Nações Unidas e as organizações não-governamentais. Destaca-se o número 5:

\begin{abstract}
Relações de consulta podem ser estabelecidas com organizações nacionais, subregionais, regionais ou internacionais, em conformidade com a Carta das Nações Unidas e os princípios e critérios estabelecidos na presente resolução. A Comissão, ao considerar solicitações de status consultivo, deve assegurar, na medida do possível, a participação de organizações nãogovernamentais de todas as regiões, e particularmente dos países em desenvolvimento, a fim de permitir que se alcance o envolvimento genuíno, efetivo, balanceado e justo das organizações não-governamentais de todas as regiões e áreas do mundo. A Comissão deve também ter especial atenção a organizações não-governamentais que tenham especial competência técnica ou experiência sobre questões que a Comissão deseje estabelecer.
\end{abstract}

O fato é que a governança ou a boa governança não pode ser tratada como uma ação isolada da sociedade civil buscando garantir participação e influência nas decisões. Na verdade, o conceito preceitua uma ligação entre Estado e sociedade que em uma ação conjunta devem trabalhar de forma a alcançar soluções e resultados para problemas comuns.

Não se contesta o fato que para se ter a verdadeira governança é indispensável a integração sociedade, instituições e Estados. Neste sentido Leff (2004) defende que é necessário uma racionalidade:

\footnotetext{
a racionalidade ambiental não é a extensão da lógica do mercado à capitalização da natureza, mas a resultante de um conjunto de significações, normas, valores, interesses e ações socioculturais; é a expressão do conflito entre o uso da lei (do mercado) por uma classe, a busca do bem comum com a intervenção do Estado e a participação da sociedade civil num processo de reapropriação da natureza, orientando seus valores e potenciais para um desenvolvimento sustentável e democrático (LEFF, 2004, p. 143).
}

Gauchet (2002, p. 330) sustentou que "os direitos humanos se tornaram efetivamente, por uma imprevisível evolução de nossas sociedades, a norma organizadora da consciência coletiva e o padrão da ação pública" (GAUCHET, 2002, p. 330).

Para o Direito, a governança tem a ver com a presença crescente desses atores no cenário político e social. Trata-se de estabelecer regras e normas para sua participação, ainda que não com formalização institucional estrita. Trata-se de reconhecer, no campo do Direito internacional, a presença crescente desses atores na discussão e formulação de tratados, convenções e resoluções, bem como na sua implementação efetiva.

Para evitar uma catástrofe ainda maior é necessário aceitar que não é possível prever o futuro, e que as conjecturas podem acabar por resultar em uma verdadeira perda para todos, Lovelock (2006, p. 19) afirma a necessidade de evoluir com relação ao sistema da Terra: 


\begin{abstract}
A ciência busca ser global e mais do que uma coleção dispersa de disciplinas separadas, mas mesmo os que adotam uma abordagem sistêmica da ciência seriam os primeiros a admitir que nossa compreensão do sistema da Terra não é muito superior a de um médico do século XIX em relação ao seu paciente (LOVELOCK, 2006, p. 19).
\end{abstract}

Nesse sentido ao apelar à todos por um cuidado com a casa comum o Papa destaca a importância da participação da sociedade para que os objetivos sejam alcançados: "aqueles que lutam com vigor por resolver as dramáticas consequências da degradação ambiental na vida dos mais pobres do mundo" (PAPA FRANCISCO, 2015, p. 13).

Para Boff (2003), deveria existir uma ética mundial no intuito do cuidado:

O cuidado expressa a importância da razão cordial, que respeita e venera o mistério que se vela e revela em cada ser do universo e da Terra. Por isso, a vida e o jogo das relações só sobrevivem se forem cercados de cuidado, de desvelo e de atenção. A pessoa se sente envolvida afetivamente e ligada estreitamente ao destino do outro e de tudo o que for objeto de cuidado. Por isso o cuidado provoca preocupação e faz surgir o sentimento de responsabilidade (BOFF, 2003, p. 85).

O sentido de responsabilidade de todos e participação só é possível através de mecanismos que facilitem a integração da população e a administração pública e é com esse papel que o CNJ se faz um órgão necessário não apenas de controle, mas também de transparência e participação para todos.

Busca-se cumprir primeiramente com o direito de todos terem acesso às informações, previsto no art. $5^{\circ}$, inciso XIV ${ }^{10}$, inciso XXXIII ${ }^{11}$ e inciso XXXIV ${ }^{12}$, da CR/1988. De outro lado, o dever de o Poder Público informar todos os seus atos, justificando-os e os tornando público.

Segundo Sachs $(2002$, p.15) a sustentabilidade social acontece através da melhoria da qualidade de vida da população, equidade na distribuição de renda e de diminuição das diferenças sociais, com participação e organização popular; já a sustentabilidade econômica também envolve $\mathrm{o}$ acesso à ciência e tecnologia.

Mesmo presenciando todo o desgaste e a degradação do meio ambiente, os cientistas ainda tentam justificar a realidade do meio ambiente e buscam achar alternativas que continuem propiciando a exploração do mesmo. Com relação a ciência, Lovelock (2006, p. 18) entende que enquanto não existir um verdadeiro diálogo entre os conhecimentos os cientistas não possuem condições de terem uma visão ampla:

Esta não foi totalmente culpada, pois a própria ciência foi prejudicada, nos últimos
dois séculos, por sua divisão em muitas disciplinas diferentes, cada qual limitada a ver
apenas uma faceta minúscula do planeta, sem uma visão coesa da Terra. Os cientistas já
reconheceram a Terra com entidade auto reguladora na declaração de Amsterdã, em 2001 ,
e muitos ainda agem como se nosso planeta fosse uma enorme propriedade pública que
possuímos e compartilhamos (LOVELOCK, 2006, p. 18).

É necessária uma comunicação entre os conhecimentos a fim de que se possa alcançar a governança, "pela via da articulação de diversos campos do conhecimento, sem olhar para os obstáculos epistemológicos e para os interesses disciplinares que resistem e impedem tal via de completude" (LEFF, 2012, p. 32). 
A governança não é algo apenas para ser admirado, mas sim para ser vivido de forma a propiciar a todos o que é direito de todos.

\section{Considerações finais}

Buscou-se analisar neste artigo o direito ao desenvolvimento e a governança como possibilidade de uma sustentabilidade que hoje o mundo clama. Observar a necessidade de uma verdadeira participação de todos nas tomadas de decisões, transformando as pessoas em verdadeiros fiscais do desenvolvimento se faz necessário a medida que a atitude de um afeta diretamente a existência do outro.

Trazer o apelo do Papa Francisco como forma de demonstrar a realidade existente foi apenas uma tentativa de visualizar que o meio ambiente clama de maneira tão forte que nem mesmo a religião pode se esquivar de convocar a todos à participarem de maneira efetiva na preservação de "nossa casa".

Os direitos fundamentais, a garantia de participação de todos, a transparência e a justiça social se encontram no direito ao desenvolvimento como no que se chama de boa governança.

No sentido que ambos necessitam de todos esses quesitos para se efetivarem de forma plena e surtirem os efeitos desejados por todos.

No entanto a efetivação da governança só existira no dia que o Processo Judiciário eletrônico respeitar de forma indiscriminada o respeito à informação de todos, passando a trabalhar com transparência e objetividade.

Diante da realidade existente, a sustentabilidade não é mais uma opção, passou a ser a única forma de garantir para a humanidade e para as gerações futuras um meio ambiente equilibrado e saudável. Assim, faz todo o sentido todos participarem das decisões, todos terem acesso às informações de forma transparente e, ainda, todos compreenderem que cada um é responsável por suas atitudes, e que elas, ainda que lhes pareçam insignificantes, acabam por contribuir no resultado final. Então que todos possam se unir para a defesa mundial de forma que seja garantido a todos o direito do desenvolvimento, bem como uma efetiva participação e ainda um meio ambiente equilibrado.

Com isso, se tem que por mais que o Conselho Nacional de Justiça implemente resoluções em busca da efetivação de uma boa governança, essa só sera alcançada com uma maior participação de todos.

Ao se fazer mais sentido ainda um Poder Judiciário digital existente nos moldes de uma boa governança, com um meio ambiente.

\section{Notas}

1 Trabalho financiado pelo Edital $n^{\circ}$ 05/2016 (Projeto $n^{\circ}$ FIP 2016/11173-S2) do FIP/PUC MINAS, resultante dos Grupos de Pesquisas (CNPQ): Regulação Ambiental da Atividade Econômica Sustentável (REGA) e CEDIS (FCT-PT).

2 Mestre em Direito pela Escola Superior Dom Helder Câmara e se especializando em direito eleitoral na Pontifícia Universidade Católica de Minas Gerais. Graduou em DIREITO pela Pontifícia Universidade 
Católica de Minas Gerais (2006). Tem experiência na área de Direito, com ênfase em Direito Trabalhista Prêmios de destaque Universitário. Sócia titular do Estanislau Assessoria e Consultoria Jurídica, exercendo a advocacia ininterruptamente, desde 2006, tendo sido inscrita como estagiária de 2004 a 2006. E-mail: fernandaestanislau@yahoo.com.br

3 Pós-doutor em Direito Público e Educação pela Universidade Nova de Lisboa-Portugal. Pós-doutor em Direito Civil e Processual Civil, Doutor em Direito e Mestre em Direito Processual, pela Universidad de Deusto-Espanha. Mestre em Educação pela PUC Minas. Professor do Mestrado Acadêmico em Direito Ambiental e Sustentabilidade na Escola Superior Dom Helder Câmara. Professor Adjunto da PUC Minas e Professor Titular licenciado da Faculdade de Direito Arnaldo Janssen. Advogado Sócio do Escritório Raffaele \& Federici Advocacia Associada. Integrante dos grupos de pesquisa: Regulação Ambiental da Atividade Econômica Sustentável (REGA)/CNPQ-BRA e Centro de Investigação \& Desenvolvimento sobre Direito e Sociedade (CEDIS)/FCT-PT. ORCID: < http://orcid.org/0000-0002-4711-5310>. E-mail: federici@pucminas.br

4 Art. $5^{\circ}, \mathrm{CR} / 1988$ - Todos são iguais perante a lei, sem distinção de qualquer natureza, garantindo-se aos brasileiros e aos estrangeiros residentes no País a inviolabilidade do direito à vida, à liberdade, à igualdade, à segurança e à propriedade, nos termos seguintes: [...] XXXIV - são a todos assegurados, independentemente do pagamento de taxas: a) o direito de petição aos Poderes Públicos em defesa de direitos ou contra ilegalidade ou abuso de poder; b) a obtenção de certidões em repartições públicas, para defesa de direitos e esclarecimento de situações de interesse pessoal; XXXV - a lei não excluirá da apreciação do Poder Judiciário lesão ou ameaça a direito; XXXVI - a lei não prejudicará o direito adquirido, o ato jurídico perfeito e a coisa julgada; XXXVII - não haverá juízo ou tribunal de exceção [...] (BRASIL, 1988).

5 Art. $5^{\circ}$, inciso XIV, CR/1988: é assegurado a todos o acesso à informação e resguardado o sigilo da fonte, quando necessário ao exercício profissional (BRASIL, 1988).

6 Art. $5^{\circ}$, inciso XXXIII, CR/1988: todos têm direito a receber dos órgãos públicos informações de seu interesse particular, ou de interesse coletivo ou geral, que serão prestadas no prazo da lei, sob pena de responsabilidade, ressalvadas aquelas cujo sigilo seja imprescindível à segurança da sociedade e do Estado (BRASIL, 1988).

7 Art. $5^{\circ}$, inciso XXXIV, CR/1988: são a todos assegurados, independentemente do pagamento de taxas: a) o direito de petição aos Poderes Públicos em defesa de direitos ou contra ilegalidade ou abuso de poder; b) a obtenção de certidões em repartições públicas, para defesa de direitos e esclarecimento de situações de interesse pessoal (BRASIL, 1988).

8 Art. $5^{\circ}, \mathrm{CR} / 1988$ : Todos são iguais perante a lei, sem distinção de qualquer natureza, garantido -se aos brasileiros e aos estrangeiros residentes no País a inviolabilidade do direito à vida, à liberdade, à igualdade, à segurança e à propriedade, nos termos seguintes: [...] X - são invioláveis a intimidade, a vida privada, a honra e a imagem das pessoas, assegurado o direito a indenização pelo dano material ou moral decorrente de sua violação (BRASIL, 1988).

9 BRASIL. Supremo Tribunal Federal. Mandado de Segurança n ${ }^{\circ}$ 23.452/RJ. Rel. Min. Celso de Mello, Brasília, 01 jun. 1999. Diário de Justiça, Brasília, 08 jun. 1999. Disponível em: < http://www.stf.jus.br>. Acesso em: 07 dez. 2016.

10 Art. $5^{\circ}$, inciso XIV, da CR/1988: é assegurado a todos o acesso à informação e resguardado o sigilo da fonte, quando necessário ao exercício profissional (BRASIL, 1988).

11 Art. 5º, inciso XXXIII, da CR/1988: todos têm direito a receber dos órgãos públicos informações de seu interesse particular, ou de interesse coletivo ou geral, que serão prestadas no prazo da lei, sob pena de responsabilidade, ressalvadas aquelas cujo sigilo seja imprescindível à segurança da sociedade e do Estado (BRASIL, 1988).

12 Art. $5^{\circ}$, inciso XXXIV, da CR/1988: são a todos assegurados, independentemente do pagamento de taxas: a) o direito de petição aos Poderes Públicos em defesa de direitos ou contra ilegalidade ou abuso de poder;

b) a obtenção de certidões em repartições públicas, para defesa de direitos e esclarecimento de situações de interesse pessoal (BRASIL, 1988). 


\section{Referências}

BOBBIO, Norberto. A era dos direitos. Tradução de Carlos Nelson Coutinho. Rio de Janeiro: Campus, 1992.

BOBBIO, Norberto. A teoria do Estado e do poder. In BOBBIO, Norberto. Ensaios escolhidos. São Paulo: Cardim, 1988, Cap. ?, p. 157-184.

BOFF, Leonardo. Ethos mundial: um consenso mínimo entre os humanos. Rio de Janeiro: Sextante, 2003.

BRASIL. Constituição (1988). Constituição da República Federativa do Brasil, de 05 out. 1988. 6. ed. São Paulo: AASP, 2013.

BRASIL. Conselho Nacional de Justiça. Justiça em números 2008:principais fatos e análise da série histórica.

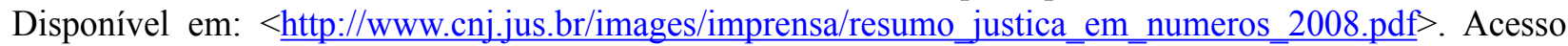
em 10.6.2016

BRASIL. Supremo Tribunal Federal. Mandado de Segurança no 23.452/RJ. Rel. Min. Celso de Mello, Brasília, 01 jun. 1999. Diário de Justiça, Brasília, 08 jun. 1999. Disponível em: <http://www.stf.jus.br>. Acesso em: 07 dez. 2016.

COMISSÃO MUNDIAL SOBRE O MEIO AMBIENTE E DESENVOLVIMENTO (CMMAD). Nosso futuro comum. Rio de Janeiro: Fundação Getúlio Vargas, 1988.

DINIZ, Eli. Governabilidade, democracia e reforma do Estado: os desafios da construção de uma nova ordem no Brasil dos anos 90. Dados - Revista de Ciências Sociais, Rio de Janeiro, v. 38, n 3, p. 385-415, 1995.

FACHIN, Melina Girardi. Direito fundamental ao desenvolvimento: uma possível ressignificação entre a Constituição Brasileira e o Sistema Internacional de Proteção dos Direitos Humanos. In: PIOVESAN, Flávia; SOARES, Inês Virgínia Prado (Coord.). Direito ao desenvolvimento. Belo Horizonte: Fórum, Parte I, p.179-198, 2010.

GAUCHET, Marcel. La démocratie contre elle-même. Paris: Gallimard, 2002.

GUERRA, Sidney. Desenvolvimento sustentável nas três grandes conferências internacionais de ambiente da ONU: o grande desafio no plano internacional. In: GOMES, Eduardo B.; BULZICO, Bettina (Orgs.). Sustentabilidade, desenvolvimento e democracia. Ijuí: Unijuí, 2006.

LEFF, Enrique. A complexidade ambiental. São Paulo: Cortez, 2003.

LEFF, Enrique. Aventuras da epistemologia ambiental: da articulação das ciências ao diálogo de saberes. São Paulo: Cortez, 2012.

LEFF, Enrique. Epistemologia ambiental. 3. ed. São Paulo: Cortez, 2002.

LEFF, Enrique. Racionalidade ambiental: a reapropriação social da natureza. Rio de Janeiro: Civilização Brasileira, 2006.

LEFF, Enrique. Saber ambiental: sustentabilidade, racionalidade, complexidade, poder. 3. ed. Petrópolis: Vozes, 2004.

LOCKE, John. O Segundo Tratado sobre o Governo Civil. Tradução: Magda Lopes e Marisa Lobo da Costa. Editora Vozes: Petrópolis, 1994.

LOVELOCK, James. A vingança de gaia. Tradução de Ivo Korytowski. Rio de Janeiro: Intrínseca, 2006.

MARKS, Stephen P. Obligations to implement the right to development: philosphical, political and legal rationales. Direito ao desenvolvimento. Belo Horizonte: Fórum, 2010.

PAPA FRANCISCO. Carta Encíclica 'Laudato si' do santo padre Francisco. Sobre o cuidado da casa comum. Vatican. Disponível em: <http://w2.vatican.va/content/ dam/francesco/pdf/encyclicals/documents/ papafrancesco_20150524_enciclicalaudato-si_po.pdf $>$. Acesso em: 17 jun. 2016. 
PIOVESAN, Flávia Cristina. Direitos humanos e o direito constitucional internacional. 4. ed. São Paulo: Max Limonad, 2000.

PIOVESAN, Flávia Cristina. Direito ao desenvolvimento: desafios contemporâneos. In: PIOVESAN, Flávia; SOARES, Inês Virgínia Prado (Coord.). Direito ao desenvolvimento. Belo Horizonte: Fórum, Parte I, p. 95-116

SACHS, Ignacy. Caminhos para o desenvolvimento sustentável. Rio de Janeiro: Garamond, 2002.

SAMPAIO, José Adércio Leite. Conselho Nacional de Justiça e a independência do Judiciário. Belo Horizonte: Del Rey, 2007.

SANTOS, Maria Helena de Castro. Governabilidade, governança e democracia: criação da capacidade governativa e relações executivo-legislativo no Brasil pós-constituinte. Dados - Revista de Ciências Sociais, Rio de Janeiro, v. 40, no 3, p. 335-376, 1997. Disponível em: $<$ http://www.scielo.br/scielo.php?script=sci arttext\&pid=S0011-52581997000300003 > . Acesso em: 06 dez. 2016.

UN, ECOSOC, Resolução 1996/31- Consultative Relationship between the United Nations and non-governmental organisations. UN. Disponível em: <http://www.un.org/documents/ecosoc/res/1996/eres1996-31. $\underline{\mathrm{htm}}>$. Acesso em: 15 de jul. 2016.

VEIGA, José Eli da. Os desafios do desenvolvimento sustentável no Brasil. In: PADUA, José Augusto (org). Desenvolvimento, justiça e meio ambiente. Belo Horizonte: UFMG, 2009. p. 151-169.

WAMBIER, Luiz Rodrigues. Curso avançado de processo civil. 5. ed. São Paulo: RT, 2000. v. 1. 